Magazine of Concrete Research Volume 65 Issue 11

Estimating the original cement content and water-cement ratio of Portland cement concrete and mortar using backscattered electron microscopy

Wong, Matter and Buenfeld
Magazine of Concrete Research, 2013, 65(11), 693-706

http://dx.doi.org/10.1680/macr.12.00201

Paper 1200201

Received 26/10/2012; revised 08/02/2013; accepted 15/02/2013

Published online ahead of print 08/05/2013

ICE Publishing: All rights reserved

\title{
Estimating the original cement content and water-cement ratio of Portland cement concrete and mortar using backscattered electron microscopy
}

Hong Seong Wong

Lecturer, Department of Civil and Environmental Engineering, Imperial College London, UK

Kyle Matter

Graduate student, Department of Civil and Environmental Engineering, Imperial College London, UK
Nicholas R. Buenfeld

Professor of Concrete Structures, Department of Civil and Environmental Engineering, Imperial College London, UK

In a previous study, a method was proposed to estimate the cement content, water content, free water-cement ratio $(\mathrm{w} / \mathrm{c})$ and degree of hydration of hardened Portland cement pastes that have unknown proportions. The method is based on measuring the volumetric fractions of capillary pores, hydration products and unreacted cement using backscattered electron microscopy and the volumetric increase of solids during cement hydration. It has the advantage that it is quantitative and does not require comparison with reference samples made with the same materials and cured to the same hydration degree as the unknown sample. However, the method was tested on neat cement pastes only, hence limiting its practical application. In this paper, the extension of the method to Portland cement mortars and concretes is presented, and results are provided, obtained from samples made with three cement types and a range of aggregate content (40-70\% vol.), w/c ratio (0.30-0.70) and curing age (3-90 days). The study also involved sealedcured, wet-cured and field-exposed samples. It is observed that bleeding and aggregate absorption can have a significant effect on the free w/c ratio. Overall, good agreement between the estimated and actual values is found. The error in estimating free $\mathbf{w} / \mathrm{c}$ ratio using the proposed method is no more than $\mathbf{0 . 0 5}$ for all samples tested in this study.

\section{Notation}

$c^{\prime} \quad$ mass of reacted cement

$m$ degree of hydration

$V_{\mathrm{AH}} \quad$ volume of unreacted cement

$V_{\mathrm{C}} \quad$ volume of original cement

$V_{\mathrm{CP}} \quad$ volume of capillary pores

$V_{\mathrm{HP}} \quad$ volume of hydration products

$V_{\mathrm{W}} \quad$ volume of original free water

$v_{\mathrm{c}} \quad$ specific volume of cement

$v_{\mathrm{g}} \quad$ specific volume of gel water

$v_{\mathrm{n}} \quad$ specific volume of non-evaporable water

$w_{\mathrm{n}} \quad$ mass of non-evaporable water

$w_{\mathrm{g}} \quad$ mass of gel water

$x \quad$ represents mass fractions of $\mathrm{C}_{3} \mathrm{~S}, \mathrm{C}_{2} \mathrm{~S}, \mathrm{C}_{3} \mathrm{~A}$ and $\mathrm{C}_{4} \mathrm{AF}$

$\delta_{\mathrm{V}} \quad$ volumetric ratio of hydration products to reacted cement

$\rho_{\mathrm{c}} \quad$ specific gravity of cement

\section{Introduction}

The water-cement ratio $(\mathrm{w} / \mathrm{c})$ is an important parameter in concrete mix proportioning because it influences most properties of hardened concrete, in particular strength and durability. This is due to the direct relationship between $\mathrm{w} / \mathrm{c}$ ratio and the amount of residual pore spaces, that is capillary pores, in the hardened cement paste. Concretes with high w/c ratios have high capillary porosity, low strength and poor resistance to ingress of aggressive agents that cause durability problems. As w/c ratio is indicative of the quality of a concrete, the situation arises when it is desirable to determine the original $\mathrm{w} / \mathrm{c}$ ratio of a particular concrete some time after it has hardened. This may be carried out for quality control purposes during manufacture of new concretes, forensic investigation to determine the causes of poor performance of existing concrete structures, or in disputes over suspected non-compliance with mix specification.

Once concrete has set, it is very difficult to measure the exact amounts of cement and water that were added during batching. There is yet to be a universally accepted technique for determining the original $\mathrm{w} / \mathrm{c}$ ratio of a sample taken from an existing structure. Apart from the physico-chemical method described in BS 1881-124 (BSI, 1988) and the fluorescence microscopy 
technique (Christensen et al., 1979; Jakobsen and Brown, 2006) described in the Nordisk test method NT 361 (Nordtest, 1999), there exists no other standardised test for $\mathrm{w} / \mathrm{c}$ ratio, for example, in RILEM (International Union of Laboratories and Experts in Construction Materials, Systems and Structures), EN (European Committee for Standardisation) or ASTM (American Society for Testing and Materials). However, the physico-chemical method is known to have low precision, estimated to be $0 \cdot 1$ (w/c ratio) or greater (Concrete Society, 1989; Neville, 2003; St John et al., 1998). The fluorescence method, on the other hand, relies on the use of reference standards for comparison or calibration purposes, which should be made with the same cement and aggregate type, air content and degree of hydration, in addition to $\mathrm{w} / \mathrm{c}$ ratio, as the concrete being examined (Eden, 2010; Neville, 2003; St John et al., 1998).

In a previous work (Wong and Buenfeld, 2009), the present authors proposed a new microscopy-based method to estimate the free $\mathrm{w} / \mathrm{c}$ ratio of hardened cement pastes that does not require comparison to any reference or calibration standards. The proposed method is also able to estimate the degree of hydration and the original cement content and water content separately. Preliminary testing showed encouraging results, whereby a good agreement was observed between the estimated and actual values for samples with a range of $\mathrm{w} / \mathrm{c}$ ratio $(0 \cdot 25-0 \cdot 50)$ and curing age (3-90 days). The error in determination of the w/c ratio was no more than $0 \cdot 025$. However, the original study was limited to neat cement pastes that were prepared and sealed-cured in the laboratory. Therefore, the present work was carried out to extend the proposed method to concrete and mortar samples having a range of mix proportions, curing ages and curing conditions.

\section{Methodology}

\section{Samples}

Mortars and concretes with free w/c ratios ranging from 0.30 to 0.70 were prepared using three types of Portland cement. The properties of the cements are shown in Table 1. N1 and N2 are ordinary Portland cements (CEM I) whereas cement $\mathrm{L}$ is a 'lowheat' Portland cement that has high $\mathrm{C}_{2} \mathrm{~S}$ and low $\mathrm{C}_{3} \mathrm{~A}$ contents. The phase compositions of the cements were calculated from their oxides composition using the modified form of the Bogue equation (Taylor, 1989), while the volumetric ratio of hydration products to the reacted cement $\delta_{\mathrm{v}}$ was calculated using Equation 6. The cements have very similar $\delta_{\mathrm{v}}$ values that were close to 2 .

Thirteen mixes were prepared and divided into series I and series II, representing laboratory and field samples, respectively. Series I (Table 2) consists of mortars and concretes that were made with cement N1 and Thames Valley gravel $(5-12.7 \mathrm{~mm})$ and sand $(<5 \mathrm{~mm})$ complying with the medium grading of BS 882 (BSI, 1992). The specific gravity of the sand and gravel was 2.63 and 2.53 , respectively. The concretes had $70 \%$ volume fraction of aggregates while the mortars had either $40 \%$ or $60 \%$. The amount of water needed to bring the aggregates to saturated, surface-dry condition was determined and added to the batch water to achieve the target free $\mathrm{w} / \mathrm{c}$ ratio. A sulfonated naphthalene-based superplasticiser was used to improve the workability of mixes with low $\mathrm{w} / \mathrm{c}$ ratio $(0 \cdot 3)$. The batch water was also corrected for additional water brought in by the admixture.

Mixes were batched by mass and mixed using a pan mixer. Cylindrical samples $(100 \mathrm{~mm}$ dia. $\times 250 \mathrm{~mm})$ were cast and compacted in three layers using a vibrating table. Each layer was compacted until no significant amount of air bubbles escaped the top surface. The compacted samples were covered with plastic sheets and wet hessian to prevent evaporation for the first $24 \mathrm{~h}$, then demoulded and sealed in cling film and polythene bags to cure for 3,7 and 90 days at $20^{\circ} \mathrm{C}$.

For series II (Table 3), four concrete mixes were prepared with cements N2 and L. Fine and coarse aggregates were river sand and crushed limestone with specific gravities of 2.60 and 2.65 , respectively. A water-reducing admixture (WR) and air-entraining agent (AEA) were used. The total air content of the samples as measured with point-count analysis ranged from $3 \cdot 2 \%$ to $6 \cdot 6 \%$. The samples were cast into blocks of dimension $100 \times 100 \times 400 \mathrm{~mm}$, demoulded after $24 \mathrm{~h}$ and then cured in water at $20^{\circ} \mathrm{C}$ for 28 days. After curing, the samples were exposed to the splash zone of a marine environment for 1 year.

\section{Bleed water measurement}

Bleeding was observed in some samples, particularly those with high w/c ratio, despite care taken to avoid overvibration. This is

\begin{tabular}{|c|c|c|c|c|c|c|c|c|}
\hline \multirow[t]{2}{*}{ Designation } & \multirow{2}{*}{$\begin{array}{l}\text { Specific } \\
\text { gravity }\end{array}$} & \multirow{2}{*}{$\begin{array}{l}\text { Specific surface area: } \\
\qquad \mathrm{m}^{2} / \mathrm{kg}\end{array}$} & \multicolumn{4}{|c|}{ Bogue composition: \% } & \multirow[t]{2}{*}{ LOI } & \multirow[t]{2}{*}{$\delta_{\vee}$} \\
\hline & & & $\mathrm{C}_{3} \mathrm{~S}$ & $\mathrm{C}_{2} \mathrm{~S}$ & $\mathrm{C}_{3} \mathrm{~A}$ & $\mathrm{C}_{2} \mathrm{AF}$ & & \\
\hline N1 & $3 \cdot 15$ & 342 & $63 \cdot 0$ & $12 \cdot 8$ & $7 \cdot 4$ & $8 \cdot 3$ & $1 \cdot 32$ & 2.02 \\
\hline N2 & $3 \cdot 16$ & 331 & 54.7 & $20 \cdot 4$ & $9 \cdot 5$ & 8.7 & 0.66 & $2 \cdot 12$ \\
\hline $\mathrm{L}$ & $3 \cdot 22$ & 357 & $31 \cdot 0$ & $51 \cdot 1$ & $2 \cdot 7$ & $8 \cdot 7$ & 0.64 & 1.97 \\
\hline
\end{tabular}

Table 1. Properties of the cements used in this study 


\begin{tabular}{|c|c|c|c|c|c|c|c|}
\hline Mix & Free w/c & $\begin{array}{l}\text { Water: } \\
\mathrm{kg} / \mathrm{m}^{3}\end{array}$ & $\begin{array}{l}\text { Cement: } \\
\mathrm{kg} / \mathrm{m}^{3}\end{array}$ & $\begin{array}{l}\text { SP: } \\
\%\end{array}$ & Sand: $\mathrm{kg} / \mathrm{m}^{3}$ & Gravel: kg/m³ & $\begin{array}{c}\text { Sealed curing } \\
\text { age: days }\end{array}$ \\
\hline \multicolumn{8}{|l|}{ Mortars } \\
\hline M 0.3: 40 & $0 \cdot 30$ & 292 & 964 & 0.25 & 1040 (40\% vol.) & - & 90 \\
\hline M 0.3: 60 & $0 \cdot 30$ & 193 & 642 & $1 \cdot 0$ & 1560 (60\% vol.) & - & \\
\hline M 0.5: 40 & 0.50 & 372 & 729 & - & 1040 (40\% vol.) & - & \\
\hline M 0.5: 60 & 0.50 & 253 & 486 & - & 1560 (60\% vol.) & - & \\
\hline \multicolumn{8}{|l|}{ Concretes } \\
\hline C 0.3: 70 & $0 \cdot 30$ & 166 & 482 & 0.5 & 628 (23.9\% vol.) & 1167 (46.1\% vol.) & $3,7,90$ \\
\hline C 0.4: 70 & 0.40 & 191 & 415 & - & & & \\
\hline C 0.5: 70 & 0.50 & 207 & 365 & - & & & \\
\hline C 0.6: 70 & 0.60 & 220 & 325 & - & & & \\
\hline C 0.7: 70 & 0.70 & 230 & 293 & - & & & \\
\hline
\end{tabular}

Table 2. Mix proportions of pastes, mortars and concretes from series I (laboratory samples)

\begin{tabular}{lcccccccr}
\hline Mix & Free w/c & $\begin{array}{c}\text { Water: } \\
\mathrm{kg} / \mathrm{m}^{3}\end{array}$ & $\begin{array}{c}\text { Cement: } \\
\mathrm{kg} / \mathrm{m}^{3}\end{array}$ & $\begin{array}{c}\text { WR: } \\
\%\end{array}$ & $\begin{array}{c}\text { AEA: } \\
\%\end{array}$ & $\begin{array}{c}\text { Air content: } \\
\%\end{array}$ & $\begin{array}{c}\text { Sand: } \\
\mathrm{kg} / \mathrm{m}^{3}\end{array}$ & $\begin{array}{c}\text { Limestone: } \\
\mathrm{kg} / \mathrm{m}^{3}\end{array}$ \\
\hline C 0.4-N2 & 0.40 & 160 & 400 & 1.0 & 1.5 & 4.9 & 799 & 975 \\
C 0.4-L & 0.40 & 160 & 400 & 0.8 & 1.5 & 3.2 & 802 & 978 \\
C 0.5-N2 & 0.50 & 160 & 320 & 0.8 & 1.5 & 6.6 & 830 & 1011 \\
C 0.5-L & 0.50 & 160 & 320 & 0.5 & 1.5 & 4.5 & 832 & 1014
\end{tabular}

Table 3. Mix proportions of concretes from series II (field samples)

potentially a source of error for this study as the water lost to bleeding may significantly reduce the free $\mathrm{w} / \mathrm{c}$ ratio. Two parallel samples were prepared in the same manner as before and covered to prevent evaporation. The bleed water accumulated on the top surfaces of the compacted samples was collected periodically using a pipette, according to the procedure described in BS EN 480-4:2005 (BSI, 2005). The measured bleed water was converted to value per mass of cement from the known mix proportion to give an estimate of the corrected free $\mathrm{w} / \mathrm{c}$ ratio.

\section{Backscattered electron microscopy}

An epoxy-impregnated polished block $(40 \times 20 \times 8 \mathrm{~mm})$ was prepared from the mid-height of each cylinder after the designated curing or exposure period. Sectioning was done using a diamond abrasive cutter operated at a slow feed rate of $0.3 \mathrm{~mm} / \mathrm{s}$. The field samples were sectioned at $30 \mathrm{~mm}$ away from the seawater exposed face to avoid areas that may be influenced by leaching and/or brucite precipitation. The freshly cut surfaces were tested with a phenolphthalein solution and no visible sign of carbonation was detected. The blocks were freeze-dried to remove pore water and then impregnated with a low-viscosity fluorescent-dyed epoxy. The epoxy was preheated to $50^{\circ} \mathrm{C}$ and mixed with $5 \%$ toluene to reduce its viscosity. A 2.5 bar pressure was further applied on the impregnated blocks to ensure deep penetration (Wong and Buenfeld, 2006a). The blocks were then allowed to harden over several days. Following this, they were ground using silicon carbide papers of successively finer grit size of $68,30,18$ and $14 \mu \mathrm{m}$, and then polished with diamond at 9,6, 3,1 and finally to a $0 \cdot 25$-micron finish. The grinding and polishing was carried out at $70 \mathrm{r} / \mathrm{min}$ with a $7 \mathrm{~N}$ force applied on each block. The time spent on each grinding and polishing stage was no longer than $5 \mathrm{~min}$ to minimise relief. A non-aqueous solution was used as lubricant for cutting and polishing. Cleaning was carried out with acetone in an ultrasonic bath. The polished blocks were carbon coated to prevent charging effects.

It is important to ensure that the blocks are well impregnated with epoxy in order to preserve the microstructure and to provide atomic contrast to the capillary pores. Pores not filled with epoxy will not be visible in the backscattered electron (BSE) image. Fluorescent dye is not required, but its presence helps to indicate that the surface of the polished block is saturated with epoxy. Variation in the depth of epoxy penetration has no effect on the BSE images because the sampling depth of BSEs is less than $500 \mathrm{~nm}$ at $10 \mathrm{kV}$ beam accelerating voltage (Wong and Buenfeld, 2006b).

BSE images were collected using a field-emission scanning electron microscope operated at $10 \mathrm{kV}$ accelerating voltage and $10 \mathrm{~mm}$ working distance. The images were captured at $500 \times$ magnification and digitised to $2560 \times 2048$ pixels at a pixel spacing of $0.094 \mu \mathrm{m}$, thus giving a field of view of $240 \times 192 \mu \mathrm{m}$ per image. A microanalytical standard (Al, 99.99\% purity) was 
used to calibrate the brightness and contrast settings so that the brightness histogram was centred and stretched to span the entire dynamic range of greyscale. Once the optimum setting had been found, this was applied to all images captured for the particular sample to ensure a faithful reproduction of grey values. Fifty images were collected per sample in a random and uniform manner by moving the stage in a grid fashion spanning the entire sample. The imaged areas were selected randomly so that both the bulk paste and interfacial transition zone (ITZ), that is paste near aggregate particles, were sampled. Thus, the frequency of an image containing either the ITZ, bulk paste or both depends on the aggregate size distribution and volume fraction. If a frame fell entirely on an aggregate particle, it was replaced by another randomly chosen location within the neighbouring grids. However, areas near the sample edge were not imaged to avoid sampling areas that may have been saw-damaged.

\section{Image analysis}

\section{Aggregate segmentation}

Randomly sampled BSE images of concretes and mortars will contain a considerable fraction of aggregate particles, which must first be removed before estimations of the w/c ratio and cement content can be made. However, typical aggregates contain silicarich or calcium-rich minerals with backscatter coefficients that are very similar to the cement hydrates. Thus, greyscale thresholding is ineffective because of overlap in grey values. The aggregates may be segmented using energy dispersive X-ray mapping based on a priori knowledge of the aggregate mineralogy (Brough and Atkinson, 2000; Head and Buenfeld, 2006), but this would require substantial imaging and processing time for large image sets.

A simpler and faster, yet reasonably accurate approach is to trace out the aggregate boundaries manually using a white line, threshold the white boundary, then carry out a particle detection and hole-filling operation (Figure 1). The first step is most crucial, so the image must be enlarged to enable the aggregate boundary to be marked accurately. This approach also allows the operator simultaneously to detect and segment bond cracks that sometimes appear between the aggregate and cement paste. These are drying artefacts and should not be measured as part of the original pore structure for the purpose of this study. However, it is difficult to isolate the bond cracks accurately using automated procedures because they have variable widths and do not always occur on every particle. The aggregate boundary tracing method does not require prior knowledge or assumptions made regarding the aggregate mineralogy and works well even in areas where automated procedures face difficulties (Wong and Buenfeld, 2006c). Once the aggregate boundary is accurately marked, subsequent operations are automated and defect free. This semi-manual segmentation approach requires about 1 min per image to perform.

\section{Unreacted cement and pore segmentation}

The unreacted cement, hydration products and capillary pores are then segmented to allow estimations of their volumetric fractions using stereology. The unreacted cement particles are highly contrasted from the hydration products so segmentation is relatively easy by selecting the minimum grey value between peaks for hydration products and the unreacted cement phase, as the lower threshold value (Figure 2(a) and (b)). The exact location of the minima is determined from the first derivative of the brightness histogram. The capillary pores are segmented using the 'overflow' method (Wong et al., 2006), whereby the inflection point of the cumulative brightness histogram is taken as the upper threshold value. This is obtained from the intersection of two best-fit lines in the cumulative brightness histogram (Figure 2(c) and (d)). For the purpose of this study, the capillary porosity is considered to include the hollow shell pores because Powers and Brownyard's model does not distinguish the latter pore type. Microcracks owing to damage caused by the sample preparation should not be included and care was taken to avoid imaging these areas, in particular near the sample edges. Nevertheless, the amount of microcracking observed in the samples was small and therefore considered not to have a significant influence.

The authors note that the obtained threshold values will vary slightly due to small and unavoidable fluctuations in the beam conditions, sample surface and brightness/contrast settings. However, because every image is thresholded using a consistent rule, the effect of this on the results is small. Finally, the volume fraction of hydration products is obtained by simple subtraction, taking care to exclude any entrapped or entrained air voids, which can be easily distinguished owing to their large size and spherical shape. The amount of air voids was measured using a modified point-count approach described in Wong et al. (2011).

\section{Estimating original cement content, water content and w/c ratio}

The method is summarised here and the reader is referred to Wong and Buenfeld (2009) for complete details. Figure 3 shows a schematic representation of the volumetric proportions of the main components in a hardened mortar or concrete. At any moment after setting, the hardened mortar or concrete consists of the following components: (a) the remaining unreacted cement, (b) hydration products, (c) capillary pores, (d) air voids and (e) aggregate. The sum of their volumes and any shrinkage must be equal to the sum of volumes of the original cement, free water, aggregates and air voids at the time of set. However, the amounts of aggregate and air voids are invariant with time, and the total shrinkage is small and negligible for the purpose of this study. Therefore

1. $V_{\mathrm{C}}+V_{\mathrm{W}}=V_{\mathrm{AH}}+V_{\mathrm{HP}}+V_{\mathrm{CP}}$

where $V_{\mathrm{C}}, V_{\mathrm{W}}, V_{\mathrm{AH}}, V_{\mathrm{HP}}$ and $V_{\mathrm{CP}}$ are volumes of the original cement, original free water, unreacted cement, hydration products and capillary pores. It is well known that for Portland cements cured at room temperature, the products of cement hydration occupy approximately twice the volume of reacted cement. Thus, the volumes of the original cement and water can be expressed as 
Estimating the original cement content and water-cement ratio of Portland cement concrete and mortar using backscattered electron microscopy

Wong, Matter and Buenfeld

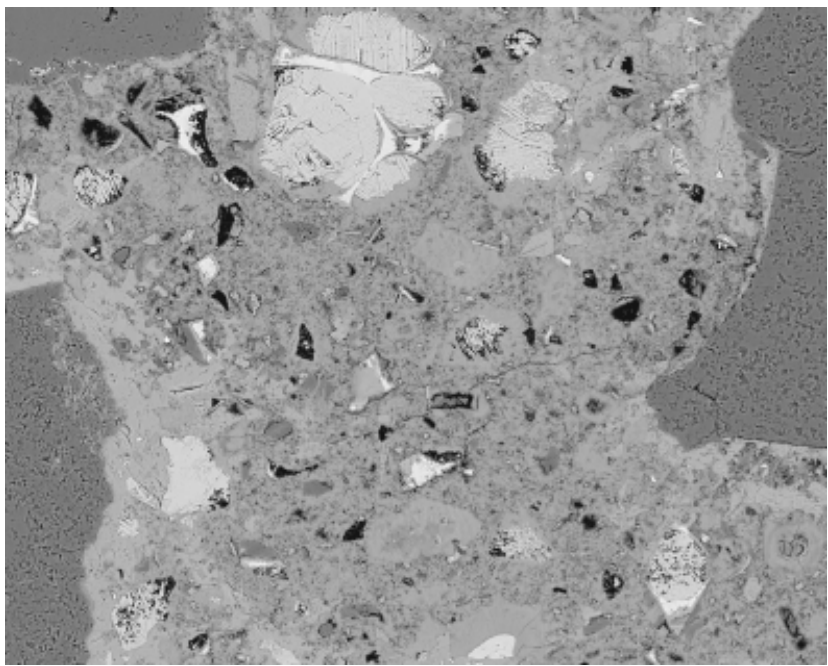

(a)

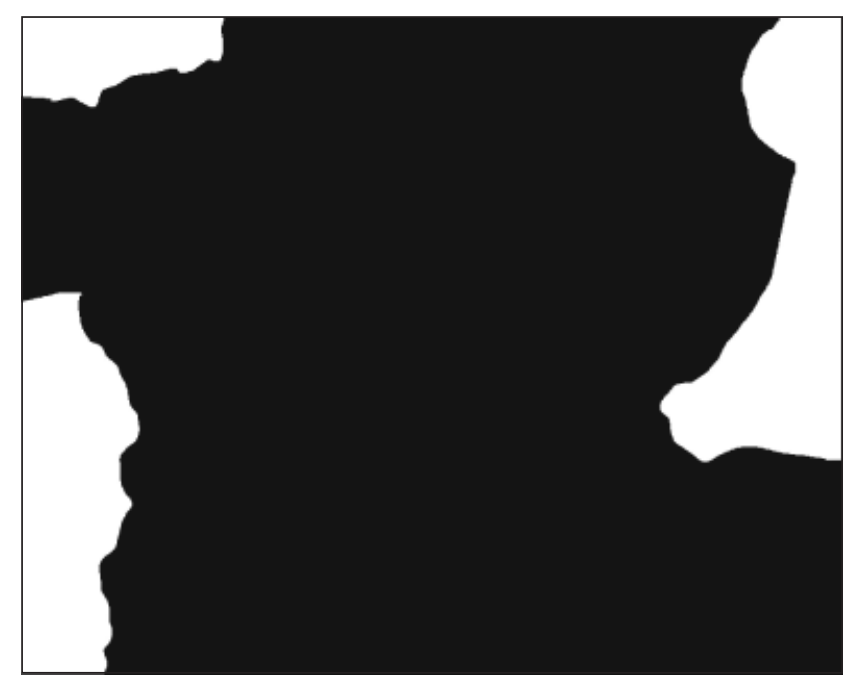

(c)

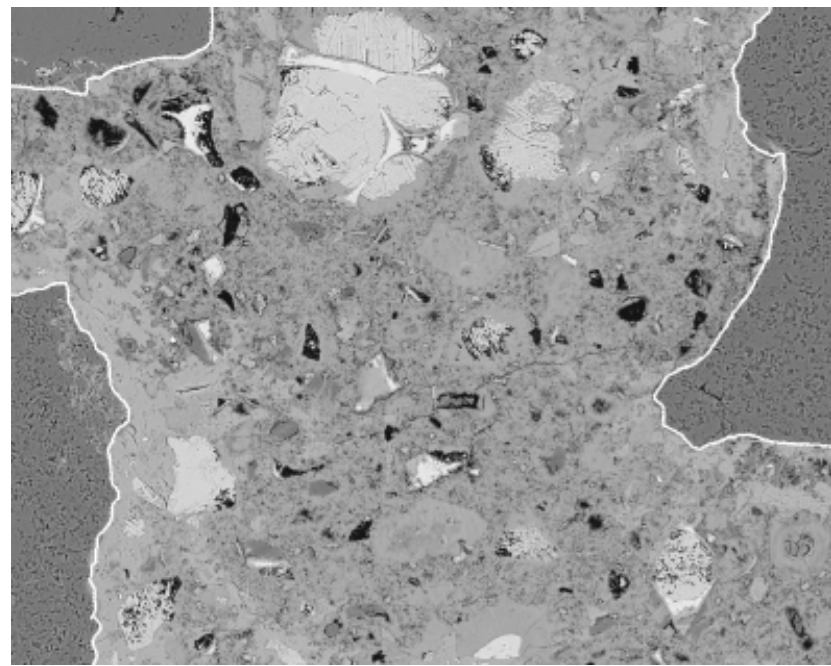

(b)

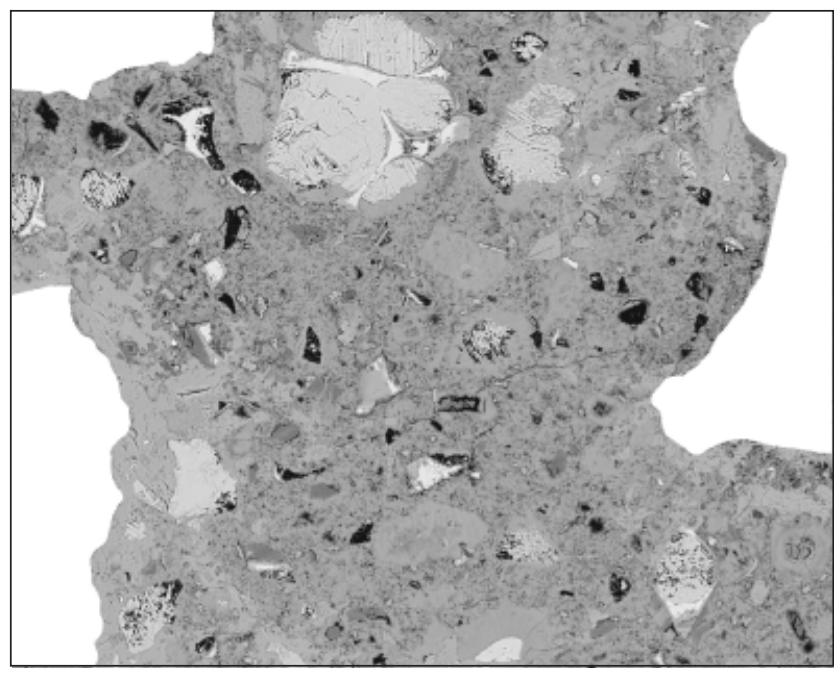

(d)

Figure 1. Aggregate segmentation: (a) original BSE image at $500 \times$ magnification; (b) aggregate boundary is manually traced with a white line; (c) thresholding, particle detection and hole filling to produce an aggregate binary mask; (d) final image with the aggregate removed. (Field of view: $240 \times 192 \mu \mathrm{m}$, sample is C 0.4-N2)

2. $V_{\mathrm{C}}=V_{\mathrm{AH}}+\frac{V_{\mathrm{HP}}}{\delta_{\mathrm{V}}}$

$$
\begin{aligned}
V_{\mathrm{W}} & =V_{\mathrm{AH}}+V_{\mathrm{HP}}+V_{\mathrm{CP}}-\left(V_{\mathrm{AH}}+\frac{V_{\mathrm{HP}}}{\delta_{\mathrm{V}}}\right) \\
& =V_{\mathrm{HP}}\left(1+\frac{1}{\delta_{\mathrm{V}}}\right)+V_{\mathrm{CP}}
\end{aligned}
$$$$
3 .
$$

where $\delta_{\mathrm{V}}$ is the volumetric ratio of hydration products to the reacted cement $(\sim 2)$.

Thus, the free $\mathrm{w} / \mathrm{c}$ ratio and the degree of hydration $(m)$ can be expressed as

4. $\frac{w}{c}=\frac{V_{\mathrm{W}}}{V_{\mathrm{C}} \rho_{\mathrm{c}}}=\frac{V_{\mathrm{HP}}\left(\delta_{\mathrm{V}}-1\right)+\delta_{\mathrm{V}} V_{\mathrm{CP}}}{\left(\delta_{\mathrm{V}} V_{\mathrm{AH}}+V_{\mathrm{HP}}\right) \rho_{\mathrm{c}}}$ 
Estimating the original cement content

and water-cement ratio of Portland

cement concrete and mortar using

backscattered electron microscopy

Wong, Matter and Buenfeld

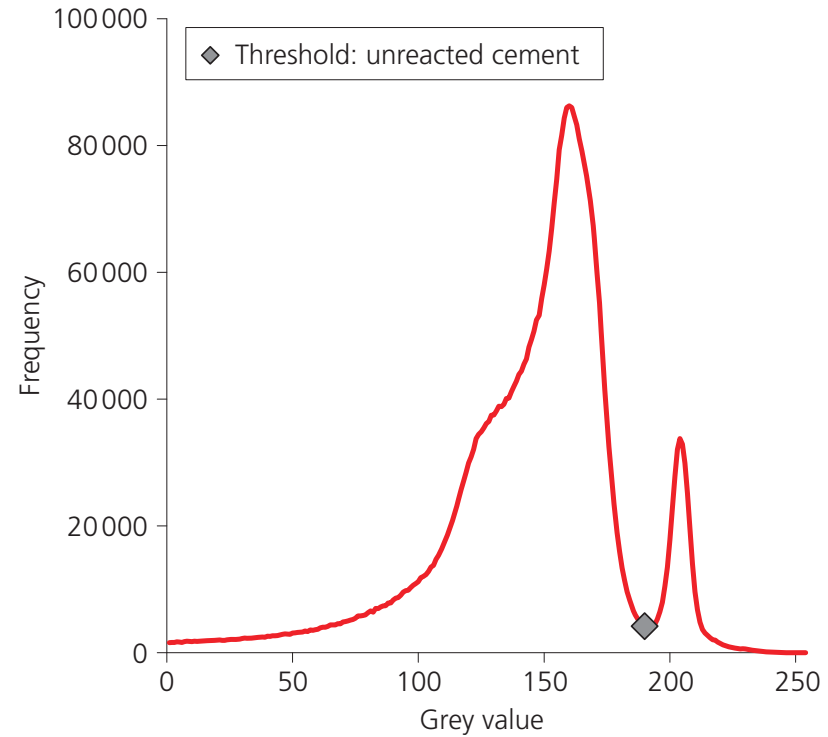

(a)

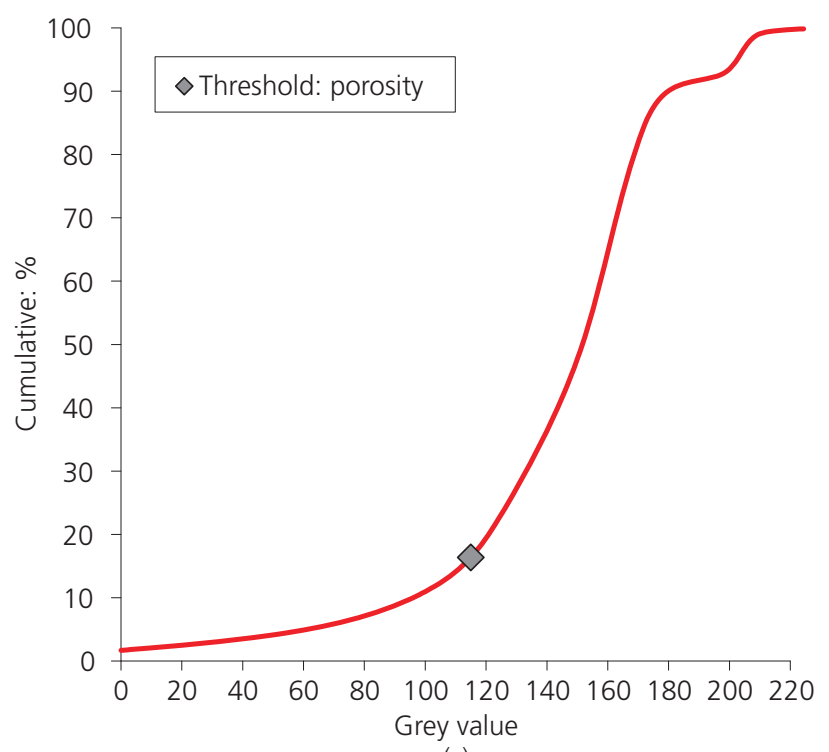

(c)

Figure 2. Segmentation of the unreacted cement can be seen in (a) and (b), and porosity in (c) and (d). The threshold for unreacted cement is selected from the minimum between peaks for hydration products and unreacted cement on the brightness histogram. The threshold for pores is estimated from the inflection point of the cumulative brightness histogram. (a) Brightness of histogram of Figure 1(a). (b) Detected unreacted cement by thresholding between 190 and 255; $V_{A H}=10.3 \%$ paste.

(c) Cumulative brightness histogram of Figure 1(d). (d) Detected porosity by thresholding between 0 and $115 ; V_{C P}=11.9 \%$ paste

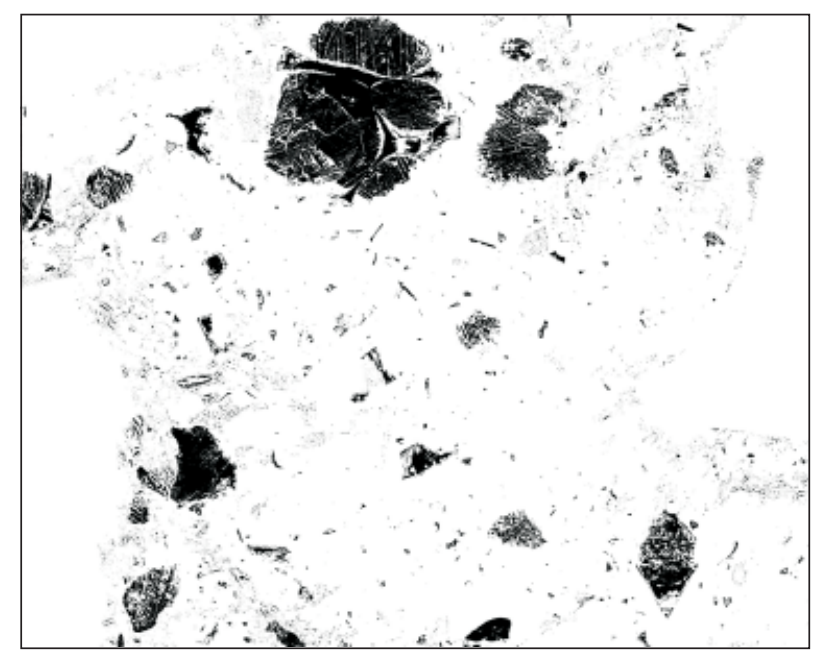

(b)

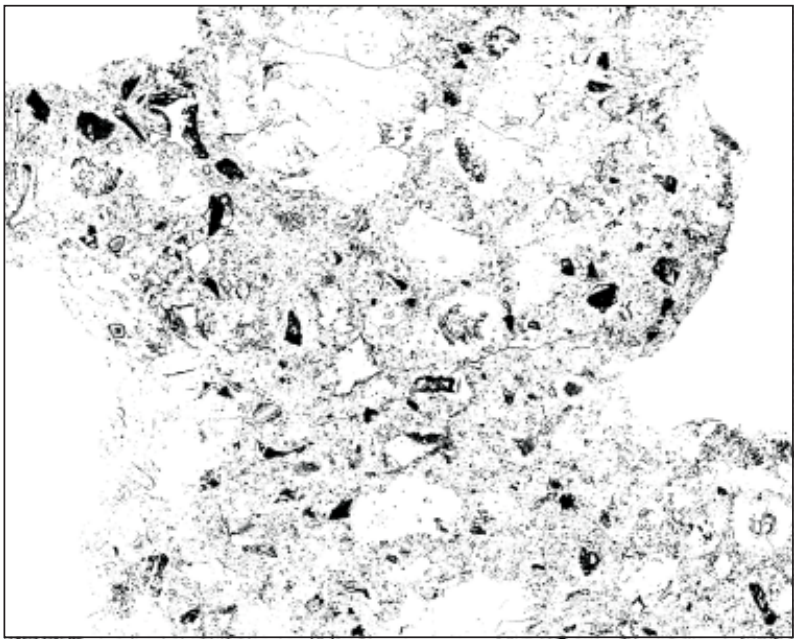

(d)
5. $m=\frac{V_{\mathrm{C}}-V_{\mathrm{AH}}}{V_{\mathrm{C}}}=\frac{V_{\mathrm{HP}}}{\delta_{\mathrm{V}} V_{\mathrm{AH}}+V_{\mathrm{HP}}}$

where $\rho_{\mathrm{c}}$ is the specific gravity of cement. As noted earlier, a good first approximation for $\delta_{\mathrm{V}}$ is 2 (Bentz, 1997; Neville, 2011; Taylor, 1997). However, the exact value of $\delta_{\mathrm{V}}$ is slightly dependent on cement composition and the present authors' previous paper (Wong and Buenfeld, 2009) has shown that this can be derived from the work of Powers and Brownyard (1947). 


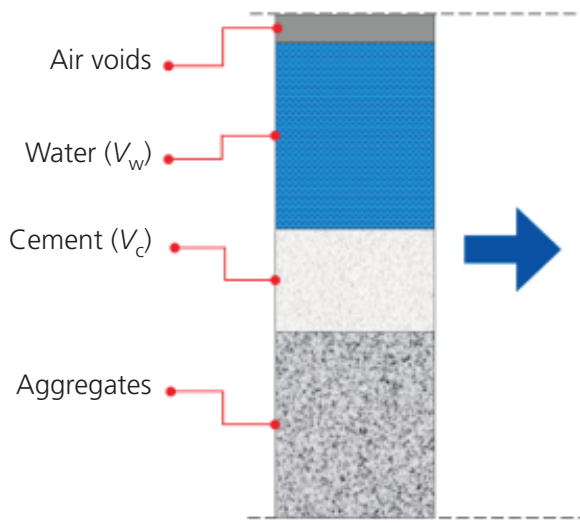

(a)

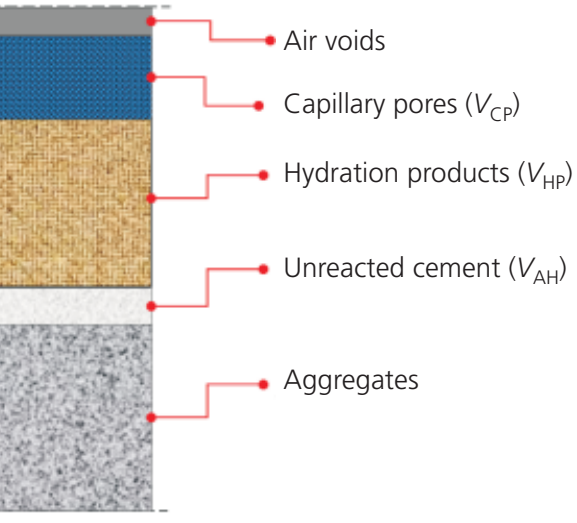

(b)

Figure 3. Schematic representation of the volumetric proportions (not to scale) of the main phases in mortar or concrete: (a) at time of initial set and (b) at time $t$ after setting

$$
\begin{aligned}
\delta_{\mathrm{V}} & =\frac{V_{\mathrm{HP}}}{V_{\mathrm{C}^{\prime}}}=\frac{c^{\prime} v_{\mathrm{c}}+w_{\mathrm{n}} v_{\mathrm{n}}+w_{\mathrm{g}} v_{\mathrm{g}}}{m c v_{\mathrm{c}}} \\
\text { 6. } \quad & =1+\frac{w_{\mathrm{n}}}{c^{\prime}} \frac{v_{\mathrm{n}}}{v_{\mathrm{c}}}+\frac{w_{\mathrm{g}}}{c^{\prime}} \frac{v_{\mathrm{g}}}{v_{\mathrm{c}}}
\end{aligned}
$$

where $c^{\prime}, w_{\mathrm{n}}$ and $w_{\mathrm{g}}$ are the mass of the reacted cement, nonevaporable water and gel water, respectively, and $v_{\mathrm{c}}, v_{\mathrm{n}}$ and $v_{\mathrm{g}}$ are the specific volumes of the cement, non-evaporable water $\left(0.72 \mathrm{~cm}^{3} / \mathrm{g}\right)$ and gel water $\left(0.9 \mathrm{~cm}^{3} / \mathrm{g}\right)$, respectively. To apply Equation 6 , the functions $w_{\mathrm{n}} / c^{\prime}$ and $w_{\mathrm{g}} / c^{\prime}$, which are the nonevaporable water per mass of hydrated cement and the gel water per mass of hydrated cement, respectively, need to be known. Powers and Brownyard (1947) showed that these can be estimated as a function of the cement mineral composition

$$
\begin{aligned}
\frac{w_{\mathrm{n}}}{c^{\prime}}= & 0 \cdot 187 x_{\mathrm{C}_{3} \mathrm{~S}}+0 \cdot 158 x_{\mathrm{C}_{2} \mathrm{~S}}+0.665 x_{\mathrm{C}_{3} \mathrm{~A}} \\
7 . \quad & +0 \cdot 213 x_{\mathrm{C}_{4} \mathrm{AF}}
\end{aligned}
$$

$$
\frac{w_{\mathrm{g}}}{c^{\prime}}=\frac{4 w_{\mathrm{n}}}{c^{\prime}} \times\left(0 \cdot 230 x_{\mathrm{C}_{3} \mathrm{~S}}+0 \cdot 320 x_{\mathrm{C}_{2} \mathrm{~S}}\right.
$$

8.

$$
\left.+0 \cdot 317 x_{\mathrm{C}_{3} \mathrm{~A}}+0 \cdot 368 x_{\mathrm{C}_{4} \mathrm{AF}}\right)
$$

where $x$ represents the mass fractions of the $\mathrm{C}_{3} \mathrm{~S}, \mathrm{C}_{2} \mathrm{~S}, \mathrm{C}_{3} \mathrm{~A}$ and $\mathrm{C}_{4} \mathrm{AF}$.

The above derivations show that the original cement content, free water content, $\mathrm{w} / \mathrm{c}$ ratio and degree of hydration can be determined, at any time after setting, from the volume fractions of the unreacted cement, hydration products and capillary pores. These can be measured directly with image analysis on BSE images. The volume fractions measured from each BSE image (section 2.4) are then used to calculate the 'local' cement content, free water content, free w/c ratio and degree of hydration, using Equations 2-5. This is repeated for a large number of images until their cumulative averages from successive frames do not vary significantly, thereby indicating that a representative volume has been analysed. The results are then converted to original cement content and water content of the concrete. To apply this method in practice for unknown concretes would require knowledge of the aggregate fraction. This can be measured accurately from point-count analysis of a representative cross-section (Wong et al., 2011).

\section{Results}

\section{Bleed water}

The amounts of bleed water measured from the mortar and concrete specimens are shown in Table 4. The measured bleed

\begin{tabular}{llll}
\hline \multirow{2}{*}{ Sample } & \multicolumn{2}{c}{ Bleed water } & $\begin{array}{c}\text { Corrected } \\
\text { free w/c }\end{array}$ \\
\cline { 2 - 3 } & Per sample: g/kg & Per cement: $g / g$ & \\
\hline M 0.5: 40 & 4.32 & 0.013 & 0.487 \\
M 0.5: 60 & 3.15 & 0.015 & 0.485 \\
M 0.3: 40 & 0.48 & 0.001 & 0.299 \\
M 0.3: 60 & 0 & 0 & 0.300 \\
C 0.7 & 6.15 & 0.05 & 0.653 \\
C 0.6 & 3.89 & 0.03 & 0.573 \\
C 0.5 & 1.06 & 0.01 & 0.494 \\
C 0.4 & 0.74 & 0 & 0.397 \\
C 0.3 & 0 & 0 & 0.300
\end{tabular}

Table 4. Results from bleed water measurement (average of two samples) to estimate the corrected free $\mathrm{w} / \mathrm{c}$ ratio 
water is converted to a value per mass of cement to determine the 'corrected' free w/c ratio. As expected, mixes with higher w/c ratio displayed a greater tendency to bleed. It can also be seen that the mortars tend to bleed more, particularly those at low sand content, compared to concretes with the same w/c ratio. Although the amount of extracted bleed water is small $(<0.7 \%)$ relative to the mass of each sample, its effect on the free $w / c$ ratio is significant. The largest reduction in the free $\mathrm{w} / \mathrm{c}$ ratio due to bleeding was $0 \cdot 05$.

\section{Unreacted cement, hydration products and porosity}

The volume fractions of unreacted cement, hydration products and capillary porosity measured from image analysis for all samples are given in Tables 5, 6 and 7. These values are averages of 50 frames per sample and normalised to the paste fraction. The authors' experience shows that the cumulative averages of the unreacted cement, hydration products and capillary porosity do not vary significantly after analysing about 50 frames, thereby indicating a representative volume has been sampled. This was found to be true for the lab-cured as well as field-exposed samples.

As expected, samples with higher $\mathrm{w} / \mathrm{c}$ ratios have higher capillary porosity and lower unreacted cement content. At the same $\mathrm{w} / \mathrm{c}$ ratio, samples that were cured for longer had lower capillary porosity and lower unreacted cement. Concretes from series II (Table 7) had the lowest capillary porosity and unreacted cement. Equivalent mortars and concretes at the same $\mathrm{w} / \mathrm{c}$ ratio and curing age showed similar values in capillary porosity and unreacted cement content. This correlation also extends to neat paste samples that were tested in the earlier study. Thus, it appears that the presence of aggregates did not make a significant difference in the measured values. Any observed differences were marginal and within measurement error or could be accounted for by the slight differences in the degree of hydration.

\begin{tabular}{lccccc}
\hline Sample & Unreacted cement: \% & Hydration products: \% & Porosity: \% & Estimated w/c & Hydration degree \\
\hline M 0.5: 40 & $6.0(0.8)$ & $69.5(2.2)$ & $24.5(2.1)$ & $0.47(0.01)$ & $0.85(0.02)$ \\
M 0.5: 60 & $5.4(0.9)$ & $67.1(1.6)$ & $27.5(1.0)$ & $0.50(0.03)$ & $0.86(0.02)$ \\
M 0.3: 40 & $19.3(1.6)$ & $65.9(2.3)$ & $14.9(1.0)$ & $0.30(0.01)$ & $0.63(0.03)$ \\
M 0.3: 60 & $20.8(1.5)$ & $64.9(1.8)$ & $14.3(0.9)$ & $0.28(0.01)$ & $0.60(0.02)$
\end{tabular}

Table 5. Measured volume fractions of unreacted cement,

hydration products and capillary porosity (average of 50 frames, normalised to paste fraction), estimated $\mathrm{w} / \mathrm{C}$ and degree of hydration for 90-day sealed-cured mortars. Values in parentheses represent the respective $95 \%$ confidence interval

\begin{tabular}{|c|c|c|c|c|c|c|c|c|c|c|c|c|c|c|c|}
\hline \multirow[t]{2}{*}{ Sample } & \multicolumn{3}{|c|}{ Unreacted cement: \% } & \multicolumn{3}{|c|}{ Hyd. products: \% } & \multicolumn{3}{|c|}{ Porosity: \% } & \multicolumn{3}{|c|}{ Estimated w/c } & \multicolumn{3}{|c|}{ Hydration degree } \\
\hline & 3 days & 7 days & 90 days & 3 days & 7 days & 90 days & 3 days & 7 days & 90 days & 3 days & 7 days & 90 days & 3 days & 7 days & 90 day \\
\hline & & & & & & & & & & & & & & & \\
\hline 0 & & $\begin{array}{l}5.9 \\
(0.8)\end{array}$ & & & & & & & & $\begin{array}{c}0.56 \\
(0.03)\end{array}$ & & & & & \\
\hline 0 & $\begin{array}{l}11 \cdot 8 \\
(1 \cdot 3)\end{array}$ & $\begin{array}{l}9.2 \\
(0 \cdot 9)\end{array}$ & $\begin{array}{c}6.4 \\
(0.9)\end{array}$ & & $\begin{array}{l}64 \cdot 6 \\
(1 \cdot 1)\end{array}$ & & & $\begin{array}{l}26 \cdot 2 \\
(1 \cdot 0)\end{array}$ & & $\begin{array}{c}0.52 \\
(0.02)\end{array}$ & $\begin{array}{r}0.4 \\
(0.0\end{array}$ & & $\begin{array}{c}0.69 \\
(0.03)\end{array}$ & $\begin{array}{c}0.78 \\
(0.02)\end{array}$ & \\
\hline 0.4 & $\begin{array}{l}16 \cdot 7 \\
(1 \cdot 4)\end{array}$ & $\begin{array}{l}16 \cdot 1 \\
(1 \cdot 4)\end{array}$ & $\begin{array}{l}10 \cdot 4 \\
(1 \cdot 6)\end{array}$ & $\begin{array}{l}56 \cdot 7 \\
(1.6)\end{array}$ & $\begin{array}{l}57.8 \\
(1.9)\end{array}$ & $\begin{array}{l}67.9 \\
(1.9)\end{array}$ & $\begin{array}{l}26.6 \\
(0.7)\end{array}$ & $\begin{array}{l}26 \cdot 1 \\
(1 \cdot 0)\end{array}$ & $\begin{array}{l}21 \cdot 6 \\
(1 \cdot 0)\end{array}$ & $\begin{array}{c}0.39 \\
(0.01)\end{array}$ & $\begin{array}{c}0.39 \\
(0.01)\end{array}$ & $\begin{array}{c}0.40 \\
(0.02)\end{array}$ & $\begin{array}{c}0.63 \\
(0.03)\end{array}$ & $\begin{array}{c}0.64 \\
(0.02)\end{array}$ & $\begin{array}{c}0.77 \\
(0.03)\end{array}$ \\
\hline 0.3 & $\begin{array}{l}24.4 \\
(1 \cdot 4)\end{array}$ & $\begin{array}{l}21.0 \\
(1 \cdot 4)\end{array}$ & $\begin{array}{l}16 \cdot 9 \\
(1 \cdot 6)\end{array}$ & $\begin{array}{l}50 \cdot 4 \\
(1.9)\end{array}$ & $\begin{array}{l}61.6 \\
(2.0)\end{array}$ & $\begin{array}{l}67.5 \\
(1.9)\end{array}$ & $\begin{array}{l}25 \cdot 2 \\
(0 \cdot 9)\end{array}$ & $\begin{array}{l}17.4 \\
(1.0)\end{array}$ & $\begin{array}{l}15 \cdot 6 \\
(1 \cdot 0)\end{array}$ & $\begin{array}{c}0.33 \\
(0.01)\end{array}$ & $\begin{array}{c}0.30 \\
(0.01)\end{array}$ & $\begin{array}{c}0.32 \\
(0.01)\end{array}$ & $\begin{array}{c}0.51 \\
(0.02)\end{array}$ & $\begin{array}{c}0.59 \\
(0.02)\end{array}$ & $\begin{array}{c}0.67 \\
(0.03)\end{array}$ \\
\hline
\end{tabular}

Table 6. Measured volume fractions of unreacted cement, hydration products and capillary porosity from image analysis (average of 50 frames, normalised to paste fraction), estimated $w / c$ and degree of hydration for sealed-cured concretes. Values in parentheses represent the respective $95 \%$ confidence intervals 


\begin{tabular}{|c|c|c|c|c|c|}
\hline Sample & Unreacted cement: \% & Hydration products: \% & Porosity: \% & Estimated w/c & Hydration degree \\
\hline C $0.4-\mathrm{N} 2$ & $3.7(0.5)$ & $83.8(0.5)$ & $12 \cdot 4(0 \cdot 7)$ & $0.42(0.01)$ & $0.92(0.01)$ \\
\hline C 0.4-L & $6 \cdot 8(0.5)$ & $76.9(0.6)$ & $16 \cdot 3(0 \cdot 7)$ & $0.38(0.01)$ & $0.85(0.01)$ \\
\hline $\mathrm{C} 0.5-\mathrm{N} 2$ & $2.9(0.5)$ & $76 \cdot 2(0 \cdot 7)$ & $20.9(0.9)$ & $0.51(0.01)$ & $0.93(0.01)$ \\
\hline C 0.5-L & $2 \cdot 5(0 \cdot 2)$ & $75.6(0.5)$ & $21.9(0.5)$ & $0.46(0.005)$ & $0.94(0.005)$ \\
\hline
\end{tabular}

Table 7. Measured volume fractions of unreacted cement, hydration products and capillary porosity (average of 50 frames, normalised to paste fraction), estimated $\mathrm{w} / \mathrm{c}$ and degree of hydration for concretes that were wet-cured for 28 days followed by 1 year of exposure in the splash zone of a marine environment. Values in parentheses represent the respective 95\% confidence intervals

\section{Estimated w/c ratio, cement content and water content}

Figure 4 shows the estimated w/c ratios plotted against the actual values after correcting for any bleeding effects, for all samples. The $y$-axis error bars for each data point in the figures indicate the 95\% confidence interval, calculated using Student's $t$-distribution $(=1.96 \mathrm{~s} / \sqrt{n})$. There is a reasonably good agreement between the estimated and actual w/c ratios for all samples, regardless of the sample type, aggregate content, curing age or exposure condition. The error in estimated $\mathrm{w} / \mathrm{c}$ ratio ranged from -0.04 to +0.04 $(-8 \cdot 6$ to $+8 \cdot 6 \%$ ), and the average error (absolute value) was $0 \cdot 02$. However, the maximum error in the case of mortars and concretes $(\sim 0.04)$ is higher than for pastes $(\sim 0.025)$, which was reported in Wong and Buenfeld (2009). The width of the error bars for the estimated $\mathrm{w} / \mathrm{c}$ ratio for mortars and concretes is also larger than that for the pastes, and appears to increase with w/c ratio. This suggests a larger spread in the 'local' $\mathrm{w} / \mathrm{c}$ ratios in the microstructure of the mortars and concretes, and may be partly

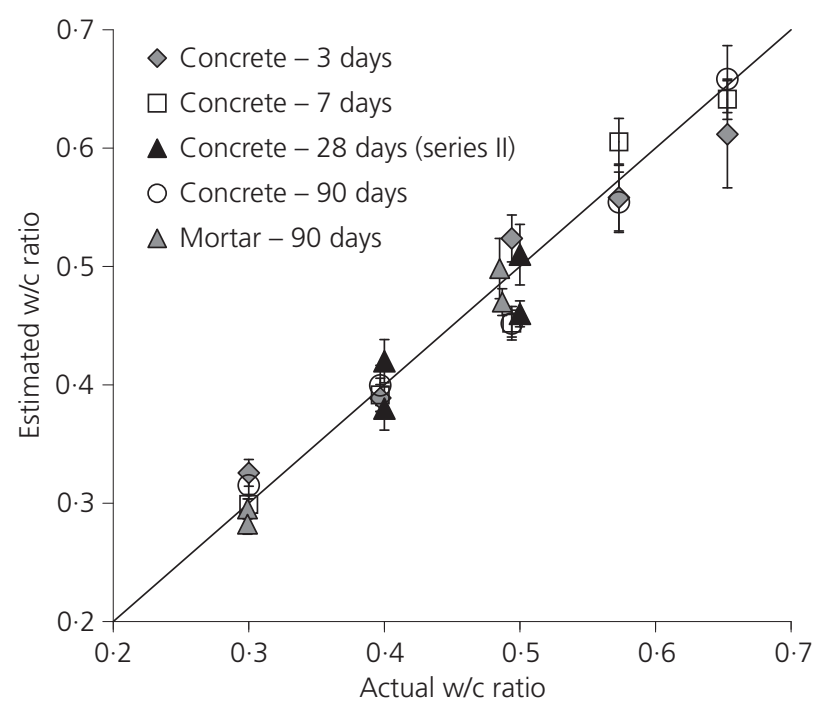

Figure 4. Comparison between the estimated and actual w/c ratio for concretes and mortars at different curing ages. The error bars represent $95 \%$ confidence interval of the averages (50 fields) attributable to bleeding effects. The presence of aggregate also increases the variability of paste microstructure owing to the particle-packing effect and micro-bleeding causing the ITZ phenomenon.

An advantage of the method is that it is able to provide estimates for the original cement content and water content. The results are shown in Figure 5. Again, a reasonable agreement is observed between the estimated and actual values. Considering that a wide range of values was covered, the method does not appear to overestimate or underestimate consistently. The errors in estimating the original cement content and water content ranged from -29 to $+33 \mathrm{~kg} / \mathrm{m}^{3}(-3 \cdot 2$ to $+10 \cdot 2 \%)$ and -8 to $+18 \mathrm{~kg} / \mathrm{m}^{3}(-5$ to $+5 \cdot 8 \%$ ), respectively. The magnitude of error for all estimations does not appear to be influenced by either the w/c ratio or curing age. However, the maximum error in the case of mortars and concretes is again higher than that for neat pastes.

\section{Variability in local w/c ratio}

The measured volume fractions from each image can be used to calculate the 'local' cement content, water content and free $\mathrm{w} / \mathrm{c}$ ratio using Equations 2-4. This is repeated for the entire set of 50 images per sample. The results are used to plot frequency distribution histograms in Figures 6 and 7 to show the spatial variability of the 'local' w/c ratio. For example, the estimated w/c ratio for sample $\mathrm{M}$ 0.3: 40 on each image was found to vary from 0.23 to 0.38 across the 50 images (Figure 6(a)). The variability in local $\mathrm{w} / \mathrm{c}$ ratio appears to increase slightly with increase in the average $\mathrm{w} / \mathrm{c}$ ratio. The variability is also higher for mortars and concretes, in comparison to pastes (compare with Figure 6 in Wong and Buenfeld (2009)). This is perhaps not surprising given the tendency to bleed at high w/c ratios and that the presence of aggregates increases the heterogeneity at the microscale. The observed variability would also depend on the magnification and field of view of the image. The variability would increase with magnification, which is a trade-off for better resolution. Nevertheless, when a representatively large number of images is measured and averaged, there appears to be a good agreement 


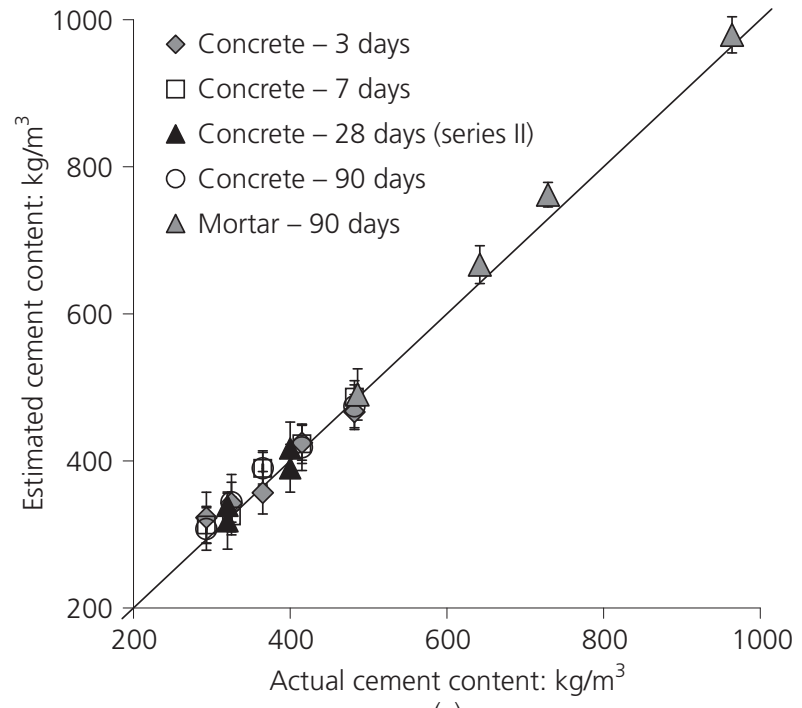

(a)

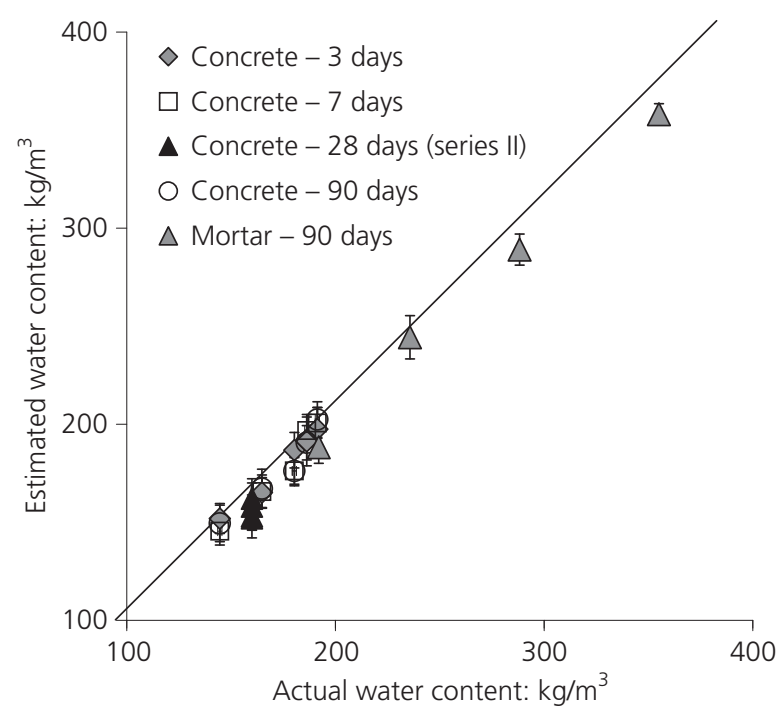

(b)

Figure 5. Comparison between the estimated and actual values for (a) original cement content and (b) water content for all samples investigated. The error bars represent $95 \%$ confidence interval of the averages (50 fields)

between the estimated and the actual values, as shown in Figures 4 and 5 .

\section{Degree of hydration}

The degree of hydration was estimated using Equation 5 and the results are shown in Tables 5-7. In Figure 8, the degree of hydration is plotted against age for all samples from series I that were sealed-cured. As expected, the degree of hydration increases with curing age, particularly in the first 7 days when a steep rise can be noted. At each age, the degree of hydration tends to be higher in samples with larger w/c ratio. Samples from series II showed the largest degree of hydration owing to

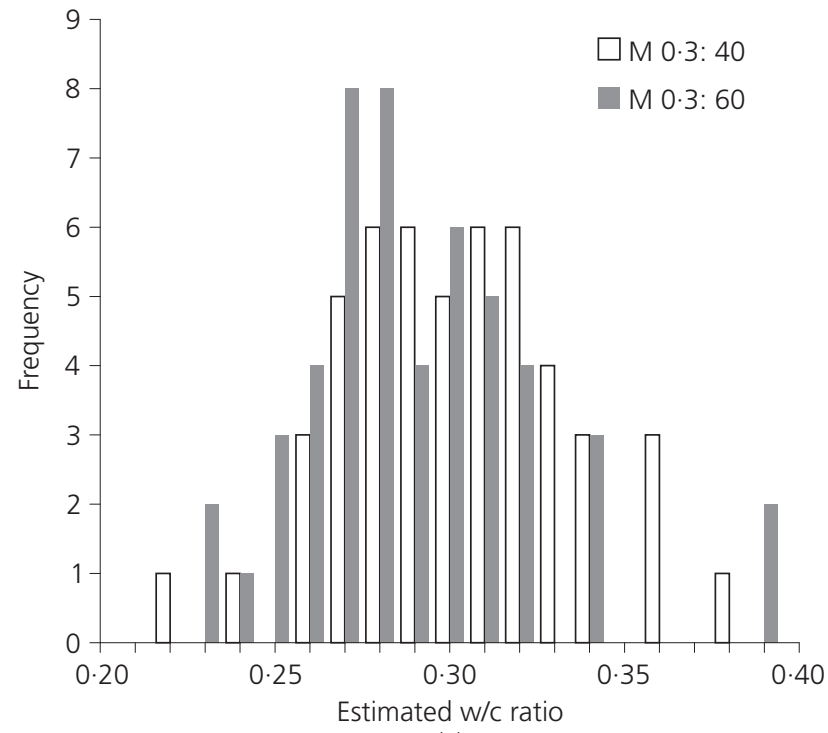

(a)

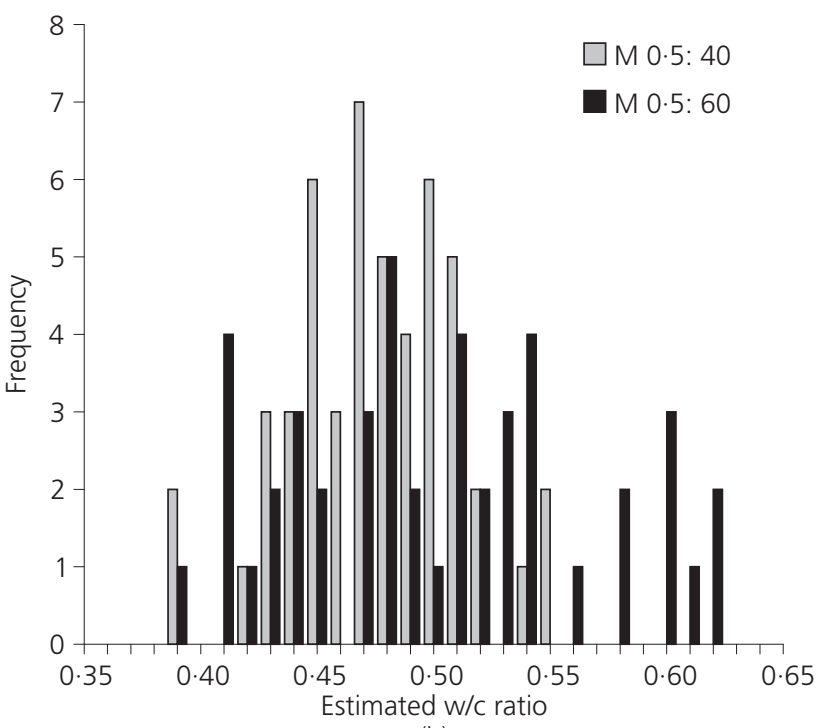

(b)

Figure 6. Frequency distribution histograms showing the spatial variability of the 'local' $w / c$ ratio in mortars: (a) $w / c=0.3$;

(b) $w / c=0.5$ the long-term exposure to water. It is interesting to note that samples C $0 \cdot 4-\mathrm{N} 2$, C $0.5-\mathrm{N} 2$ and $\mathrm{C} 0.5-\mathrm{L}$ had very similar hydration degrees $(\sim 0.92-0.94)$, but the value for $\mathrm{C} 0.4-\mathrm{L}$ was somewhat lower at $0 \cdot 85$. This could either be attributable to a measurement error or the slower reactivity of cement $\mathrm{L}$ that had high belite content.

In Figure 9, the degree of hydration of samples from series I at w/c $0.3,0.4$ and 0.5 was compared to the measured degree of hydration of equivalent paste samples cured in the same manner by the conventional method of measuring the non-evaporable water content by loss-on-ignition (LOI). This was carried out by 


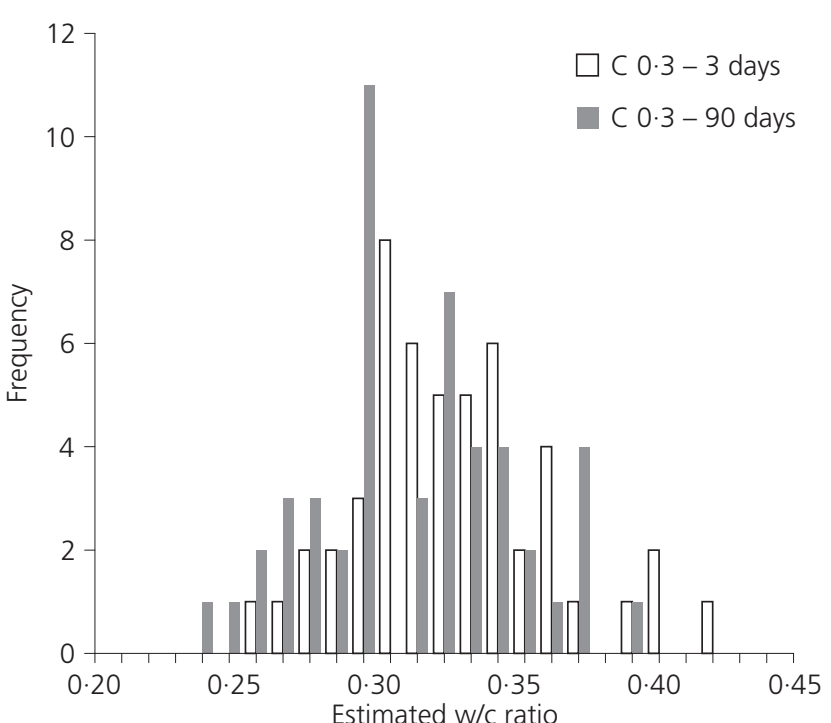

(a)

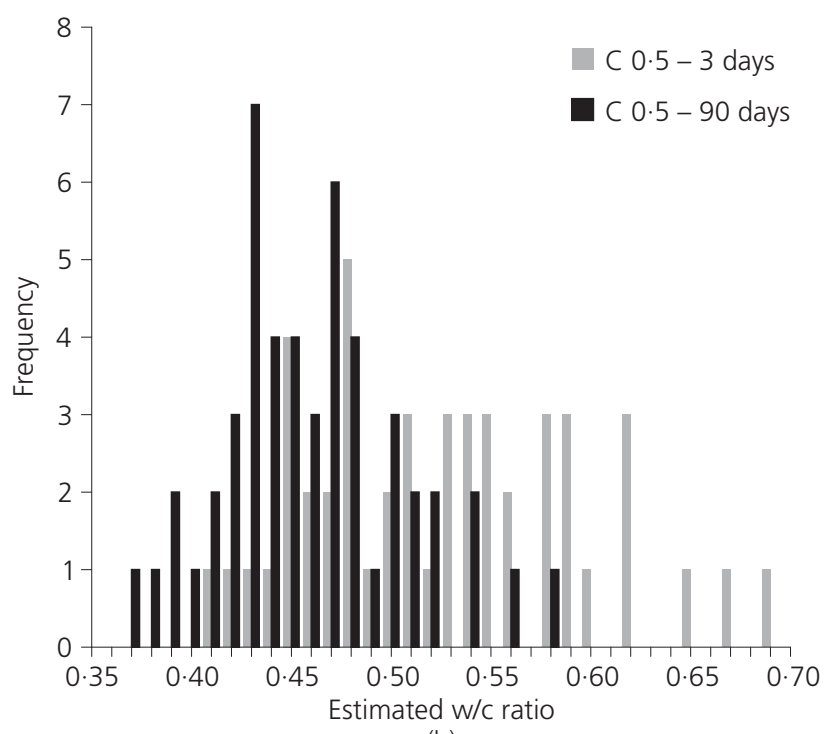

(b)

Figure 7. Frequency distribution histograms showing the spatial variability of the 'local' $w / c$ ratio in concretes: (a) $w / c=0.3$; (b) $w / c=0.5$

drying approximately $35 \mathrm{~g}$ of the equivalent paste at $105^{\circ} \mathrm{C}$ until constant mass to remove evaporable water, then crushing and heating to $1050^{\circ} \mathrm{C}$ for $3 \mathrm{~h}$. The non-evaporable water was taken as the mass loss between $105^{\circ} \mathrm{C}$ and $1050^{\circ} \mathrm{C}$, corrected for the LOI of the dry cement. The degree of hydration, $m$ (LOI), was then calculated as the ratio of the non-evaporable water content per gram of cement to the amount at complete hydration, which is equal to $0.23 \mathrm{~g} / \mathrm{g}$ for ordinary Portland cement (Brouwers, 2004; Hansen, 1986). The LOI method is not suitable for mortars and concretes because the presence of aggregates would affect its accuracy. A relatively good agreement between the proposed method and the LOI measured values was observed. The

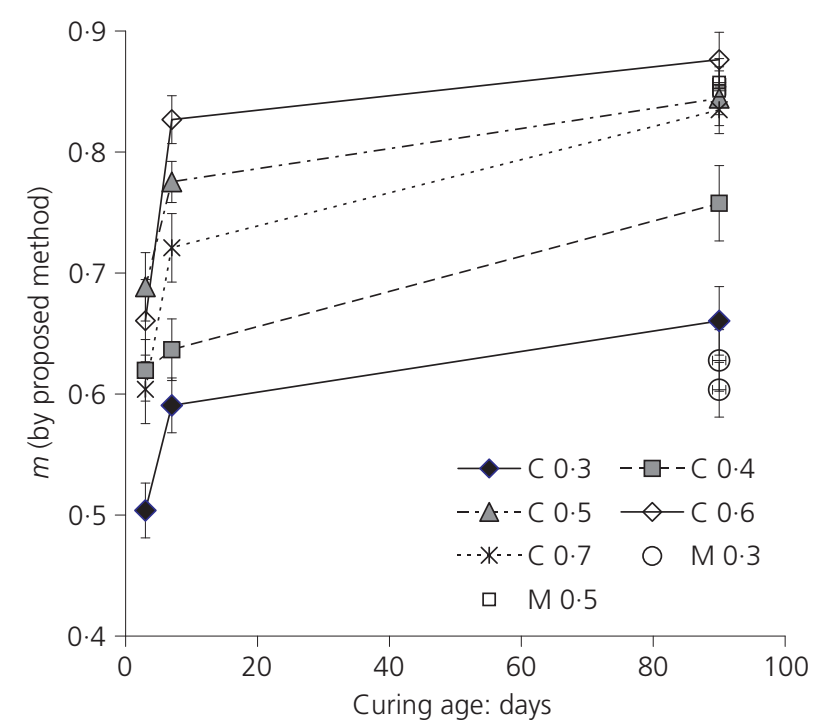

Figure 8. Variation in estimated degree of hydration with curing age for concretes and mortars from series I. The error bars represent $95 \%$ confidence interval of the averages (50 fields)

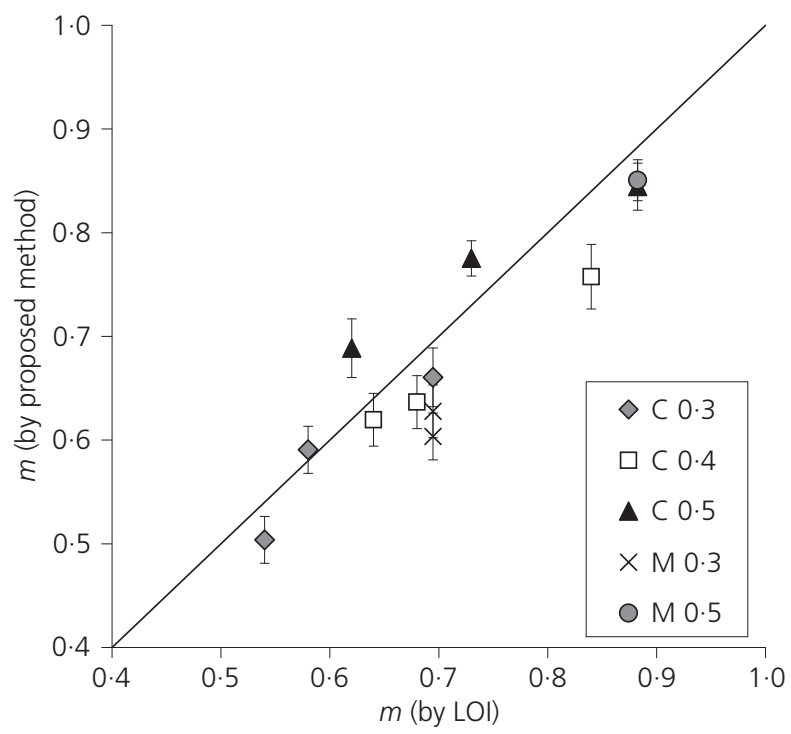

Figure 9. Comparison between the estimated degrees of hydration of samples from series I and measured degree of hydration from loss-on-ignition carried out on equivalent paste samples

discrepancy between the two measurements ranged from $-9 \cdot 8 \%$ to $11 \cdot 1 \%$. This compares well with the results from Feng et al. (2004), who estimated the degree of hydration of cement paste using a point-counting method on BSE micrographs and found an agreement of within $\pm 10 \%$ to the LOI method. 


\section{Discussion}

The results show that the proposed method for estimating original w/c ratio can be extended to hardened mortars and concretes with a range of $\mathrm{w} / \mathrm{c}$ ratio and hydration degree. The main advantage of the method is that it does not require the use of reference samples or calibration standards made with the same ingredients, w/c ratio and degree of hydration. The presence of aggregates does not influence the method because its volume fraction is constant with time. However, aggregates increase the heterogeneity of the microstructure, hence a large number of images must be analysed to obtain representative results. The method is also able to make independent estimations of the original cement, water content and degree of hydration, without having prior knowledge of the mix proportions.

Measuring the hydration degree of mortars and concretes using the LOI method is difficult because aggregates must first be removed from the paste so that the original cement content can be obtained from the mass remaining at the end of ignition. The aggregates can be separated either by crushing followed by sieving, or by dissolving the paste with concentrated acid, but neither method is very effective. As such, the hydration degree of mortars and concretes is often determined from LOI of parallel cement paste samples that have undergone the same curing regime, making the implicit assumption that both are 'equivalent'. The observed discrepancy between the proposed method and the LOI method could be attributable to errors in the measurement or simply because of actual differences between the degree of hydration of concrete and its 'equivalent' paste. The discrepancy may also be caused by partial dehydration of hydration products, particularly the $\mathrm{AFm}$ and $\mathrm{AFt}$ phases at temperatures below $105^{\circ} \mathrm{C}$ and decomposition of carbonates during ignition.

The proposed method relies on the volumetric ratio of hydration products to the reacted cement $\left(\delta_{\mathrm{V}}\right)$. However, $\delta_{\mathrm{V}}$ varies only slightly with cement type and a value of 2 is a good first approximation if the cement composition is unknown. The coefficient $\delta_{\mathrm{v}}$ may be replaced by a more comprehensive timedependent function, which could be obtained using hydration kinetics models that allow the prediction of the quantity and composition of hydrate assemblages (Lothenbach and Winnefeld, 2006; Lothenbach et al., 2008; Nielsen et al., 2005). In the current approach, the authors have used a constant $\delta_{\mathrm{V}}$ for the sake of simplicity. This implicitly assumes that the different hydration products that make up the hardened cement paste are formed at approximately the same rate and mutual proportions at all stages of hydration (Brouwers, 2004; Hansen, 1986). This approach perhaps oversimplifies the hydration kinetics, particularly at early ages, but should not severely violate the values at later ages, when the proposed method is more likely to be applied. For example, Nielsen et al. (2005) modelled the equilibrium phase assemblage in cement pastes made with three Portland cements that were wet-cured for 6 months. The calculated phase content shows that the $\delta_{\mathrm{v}}$ values for the cements were $1.94,2.02$ and 2.03. The corresponding values calculated using Equation 6 are 1.95, 2.11 and 2.03, respectively.

The main motivation for assessing the original w/c ratio of hardened concrete is to check for compliance and quality control. It is often the case that when disputes occur, samples are tested to determine if their $\mathrm{w} / \mathrm{c}$ ratio is higher than what was originally specified. Therefore, concretes with suspected high w/c ratio will be of most interest in the context of resolving disputes. However, concretes with high $\mathrm{w} / \mathrm{c}$ ratio and water content have a greater tendency to bleed. Any bleed water that rises to the top surface of a freshly compacted sample is subsequently lost to evaporation. Measurements from the present study show that although this amount is small relative to the sample weight, it can decrease the free $w / c$ ratio significantly. In poorly designed mixtures, the decrease in free w/c ratio may be even greater.

Excessive bleeding potentially creates uncertainties if one wishes to estimate the 'original' $\mathrm{w} / \mathrm{c}$ ratio, because the amount of bleeding is usually not measured on site. There is also a possible scenario in which a user justifies the addition of excess water into a mix by expecting that bleeding reduces the free $\mathrm{w} / \mathrm{c}$ ratio to the specified value. However, the quality of concrete that has experienced excessive bleeding is likely to be inferior to one that has not. Although a lower free $\mathrm{w} / \mathrm{c}$ ratio in theory should result in better strength and durability, excessive bleeding produces other undesirable effects that are detrimental to performance. For example, rising bleed water that becomes trapped on the underside of steel reinforcement creates large voids that decrease the bond between the steel and concrete, and reduce the resistance of steel to corrosion. Concrete that had excessive bleeding is expected to show a larger variability in the 'local' w/c ratio compared to one that had not, and this characteristic may be used to differentiate the two.

Similarly, the aggregates may have a significant effect on the free $\mathrm{w} / \mathrm{c}$ ratio. The extent of this depends on the aggregate content in the mix, the absorption of the aggregates and its moisture condition during batching. For example, if aggregate absorption was not taken into account in this study, the actual free $\mathrm{w} / \mathrm{c}$ ratio could be smaller than the targeted value by up to $0 \cdot 1$ owing to water lost to the aggregates. This 'error' is significant for the purpose of estimating the original $\mathrm{w} / \mathrm{c}$ ratio. The occurrence of excessive bleeding and aggregate absorption should not affect the proposed method because it is designed to measure the free $\mathrm{w} / \mathrm{c}$ ratio. However, if they are not monitored and accounted for, then the proposed method would produce results significantly different from expected values.

The proposed method is only applicable to samples that have not experienced any physical or chemical degradation. The samples must not have experienced substantial volumetric change such that Equation 1 no longer applies and reactions that may affect the porosity or alter the characteristics of the hydration products formed such as leaching and carbonation. However, the proposed 
Magazine of Concrete Research

Volume 65 Issue 11
Estimating the original cement content

and water-cement ratio of Portland

cement concrete and mortar using

backscattered electron microscopy

Wong, Matter and Buenfeld method may be applicable to samples that are poorly compacted and with entrained air by carefully excluding the air voids during image analysis. Supplementary cementitious materials such as slag and fly ash are increasingly being used in concrete. Work is currently on-going to extend the applicability of the proposed method to concretes that contain such materials.

\section{Conclusion}

A method to estimate the original cement content, water content and free $\mathrm{w} / \mathrm{c}$ ratio of hardened concretes and mortars made with Portland cement is presented. The method was tested on concretes and mortars made with three cement types, a range of $\mathrm{w} / \mathrm{c}$ ratios $(0 \cdot 30-0 \cdot 70)$, curing ages (3-90 days) and aggregate volume fractions $(40-70 \%)$. Laboratory and field-exposed samples were tested. Samples with high w/c ratios $(\geqslant 0 \cdot 5)$ tend to bleed after compaction and this can decrease the free $\mathrm{w} / \mathrm{c}$ ratio significantly. A reasonably good agreement was obtained between the estimated free $\mathrm{w} / \mathrm{c}$ ratios and the actual values, after correcting for any bleeding effects. The error in estimating free $\mathrm{w} / \mathrm{c}$ ratio using the proposed method was found to be no more than 0.05 for all the samples tested in this study.

\section{Acknowledgements}

The authors would like to thank Mr Andrew Morris for his assistance in the laboratory and Dr Kazuo Yamada (Taiheiyo Cement Corp.) for the provision of samples.

\section{REFERENCES}

Bentz DP (1997) Three-dimensional computer simulation of Portland cement hydration and microstructure development. Journal of the American Ceramic Society 80(1): 3-21.

Brough AR and Atkinson A (2000) Automated identification of the aggregate-paste interfacial transition zone in mortars of silica sand with Portland or alkali-activated slag cement paste. Cement and Concrete Research 30(6): 849-854.

Brouwers HJH (2004) The work of Powers and Brownyard revisited: Part 1. Cement and Concrete Research 34(9): 1697-1716.

BSI (1988) BS 1881: Part 124: 1988: Methods for analysis of hardened concrete. BSI, London, UK.

BSI (1992) BS 882:1992: Specification for aggregates from natural sources for concrete. BSI, London, UK.

BSI (2005) BS EN 480-4:2005: Determination of bleeding of concrete. BSI, London, UK.

Christensen P, Gudmundsson $H$, Thaulow $H$, Damgard-Jensen AD and Chatterji S (1979) Structural and ingredient analysis of concrete - methods, results and experience. Nordisk Betong 3: 4-9.

Concrete Society (1989) Analysis of Hardened Concrete. Concrete Society, Camberley, UK, Technical Report 32, p. 110.

Eden MA (2010) A Code of Practice for the Petrographic Examination of Concrete. Applied Petrography Group, London, UK, Special Report 2, see www.appliedpetrographygroup.com (accessed 26/10/2012).

Feng X, Garboczi EJ, Bentz DP, Stutzman PE and Mason TO
(2004) Estimation of the degree of hydration of blended cement pastes by a scanning electron microscope point-count procedure. Cement and Concrete Research 34(10): $1787-$ 1793.

Hansen TC (1986) Physical structure of hardened cement paste. A classical approach. Materials and Structures 19(6): 423-436.

Head MK and Buenfeld NR (2006) Measurement of aggregate interfacial porosity in complex, multi-phase aggregate concrete: binary mask production using backscattered electron, and energy dispersive X-ray images. Cement and Concrete Research 36(2): 337-345.

Jakobsen UH and Brown DR (2006) Reproducibility of w/c ratio determination from fluorescent impregnated thin sections. Cement and Concrete Research 36(8): 1567-1573.

Lothenbach B and Winnefeld F (2006) Thermodynamic modelling of the hydration of Portland cement. Cement and Concrete Research 36(2): 209-226.

Lothenbach B, Matschei T, Möschner G and Glasser FP (2008) Thermodynamic modelling of the effect of temperature on the hydration and porosity of Portland cement. Cement and Concrete Research 38(1): 1-18.

Neville AM (2003) How closely can we determine the watercement ratio of hardened concrete. Materials and Structures 36(5): 311-318.

Neville AM (2011) Properties of Concrete, 5th edn. Pearson, Harlow, UK.

Nielsen EP, Herfort D and Geiker MR (2005) Phase equilibria of hydrated Portland cement. Cement and Concrete Research 35(1): 109-115.

Nordtest (1999) NT Build 361-1999: Concrete, Hardened: Water-Cement Ratio. Nordic Innovation, Oslo, Norway, Nordtest Method, Edition 2.

Powers TC and Brownyard TL (1947) Studies of the physical properties of hardened Portland cement paste. Research Laboratory of Portland Cement Association, Skokie, IL, USA, Bulletin 22, reprinted from Journal of the American Concrete Institute (Proceedings) 43: 101-132, 249-336, 469-504, 549-602, 669-712, 845-880, 933-992.

St John DA, Poole AW and Sims I (1998) Concrete Petrography. Arnold and John Wiley, London, UK.

Taylor HFW (1989) Modification of the Bogue calculation. Advances in Cement Research 2(6): 73-77.

Taylor HFW (1997) Cement Chemistry, 2nd edn. Thomas Telford, London, UK.

Wong HS and Buenfeld NR (2006a) Patch microstructure in cement-based materials: fact or artefact? Cement and Concrete Research 36(5): 990-997.

Wong HS and Buenfeld NR (2006b) Monte Carlo simulation of electron-solid interactions in cement-based materials. Cement and Concrete Research 36(6): 1076-1082

Wong HS and Buenfeld NR (2006c) Euclidean distance mapping for computing microstructural gradients at interfaces in composite materials. Cement and Concrete Research 36(6): 1091-1097.

Wong HS and Buenfeld NR (2009) Determining the water- 
cement ratio, cement content, water content and degree of hydration of hardened cement pastes: method development and validation on paste samples. Cement and Concrete Research 39(10): 957-965.

Wong HS, Head MK and Buenfeld NR (2006) Pore segmentation of cement-based materials from backscattered electron images. Cement and Concrete Research 36(6): $1083-1090$

Wong HS, Pappas AM, Zimmerman RW and Buenfeld NR (2011) Effect of entrained air voids on the microstructure and mass transport properties of concrete. Cement and Concrete Research 41(10): 1067-1077.

\section{WHAT DO YOU THINK?}

To discuss this paper, please submit up to 500 words to the editor at www.editorialmanager.com/macr by 1 December 2013. Your contribution will be forwarded to the author(s) for a reply and, if considered appropriate by the editorial panel, will be published as a discussion in a future issue of the journal. 